\title{
Aspectos Processuais da Legislação Castelhana: as Testemunhas no Fuero Juzgo e no Fuero Real
}

\author{
Procedural Aspects of Castilian Legislation: Witnesses in Fuero Juzgo and \\ Fuero Real
}

\begin{abstract}
Mayara Ramos Saldanha ${ }^{1}$
Rosiane Graça Rigas Martins²

${ }^{1}$ Mestranda em História pela Universidade Federal Rural do Rio de Janeiro (UFRRJ) sob a orientação do Prof. Dr. Yllan de Mattos Oliveira. Graduada em História pela Universidade do Estado do Rio de Janeiro (UERJ) e membro do Programa de Estudos Medievais da UERJ (PEM-UERJ). E-mail: maysaldanha@hotmail.com.

\footnotetext{
2 Doutora em História Comparada pela Universidade Federal do Rio de Janeiro (UFRJ). Pesquisadora Associada dos Programas de Estudos Medievais da Universidade Federal do Rio de Janeiro e da Universidade do Estado
} do Rio de Janeiro (PEM-UFRJ-UERJ).E-mail: rosiane_rigas@yahoo.com.br.
\end{abstract}

Recebido em 29 de março de 2021; Aceito em 7 de junho de 2021.

DOI: $10.12957 /$ nearco.2021.58744

\section{Resumo}

Neste artigo buscamos analisar aspectos relativos ao papel das testemunhas em dois códigos jurídicos castelhanos do século XIII, o Fuero Juzgo e o Fuero Real. Procuramos fazer um estudo comparativo das leis referentes às testemunhas em ambos os fueros como forma de refletir acerca de sua influência nos processos e possíveis usos feitos pela monarquia.

Palavras-chave: Fuero Real; Fuero Juzgo; Testemunhas.

\begin{abstract}
In this article we seek to analyze aspects related to the role of witnesses in two Castilian legal codes of the thirteenth century, fuero juzgo and fuero real. We tried to make a comparative study of the laws referring to witnesses in both fueros as a way to reflect on their influence on the processes and possible uses made by the monarchy.
\end{abstract}

Keywords: Fuero Real; Fuero Juzgo; Witnesses. 


\section{Introdução}

No presente trabalho nossa proposta é analisar, em perspectiva comparada, a maneira pela qual as testemunhas são abordadas em duas fontes jurídicas castelhanoleonesas do século XIII, o Fuero Juzgo, estabelecido no reinado de Fernando III, e o Fuero Real, instituído por Afonso X, filho e sucessor do anterior. Em ambos os códices é possível encontrar títulos que discorrem especificamente sobre as atribuições das testemunhas e que estruturam as regras para a participação delas nos pleitos.

Em se tratando do estudo do processo judicial, primeiramente é necessário refletir acerca da renovação do direito que já estava em curso pelo menos desde o século XI, inicialmente no âmbito eclesiástico e nas Universidades, de onde se estenderiam, também, para as cortes reais. Uma crescente racionalização das normas jurídicas foi, aos poucos, sendo desenvolvida e, consequentemente, novas regras processuais foram sendo estabelecidas.

Se anteriormente não havia um modelo comum de provas e regras processuais que ditassem como os casos deveriam ser julgados, isso começa a mudar com o estabelecimento do Dictatus Papae por Gregório VII (1073-1085), que determinava o direito à apelação à corte papal, inviabilizando o uso de ordálios e incorporando novas formas de provas, escritas e orais (PENNINGTON, 2016, p. 126).

O uso de diferentes tipos de provas representou uma alteração significativa no sistema probatório, e aos poucos a utilização de testemunhas e documentos ganhou espaço frente aos antigos ordálios. O juiz adquiriu uma atuação mais participativa, tornando-se responsável por analisar logicamente as provas e ouvir os testemunhos, ponderando sobre eles para chegar a um juízo final.

Cabe ressaltar que essas transformações eram fundamentadas tanto no direito romano quanto no direito canônico, principalmente por tratar-se de uma empreitada iniciada por eclesiásticos. Um exemplo é o canonista Paucapalea259 que, trabalhando 
sobre o Decreto de Graciano 260, foi buscar no Gênesis e em Deuteronômio os argumentos favoráveis ao depoimento das testemunhas e recursos probatórios. Embora fossem aceitos diferentes meios de prova, como documentos ou juramentos, o testemunho era o principal (KEMMERICH, 2016, edição kindle, localização 1639).

A partir de então configurou-se, gradativamente, uma necessidade prática de organizar as regras do processo judicial. Outra obra que teve significativo destaque nesse sentido foi o Tratado de Bulgarus, eminente professor de direito romano em Bolonha, datado por volta de 1130 e que teve ampla circulação da Itália à Espanha (PENNINGTON, 2016, p. 128). Neste, estão especificados diferentes tópicos relativos ao processo como funções dos juízes, advogados, testemunhas, litigantes, tipos de litígios, entre outros.

Os tratados e escritos dos canonistas foram imprescindíveis para organizar as normas do direito romano-canônico, cujo desenvolvimento se deu de fato no ambiente universitário, de onde posteriormente saiu a maioria dos juristas especializados, clérigos ou laicos, que foram atuar nas cortes reais. A Universidade de Bolonha era expoente nesses estudos naquele momento, assim como a Universidade de Salamanca e a Escola de Tradutores de Toledo, cujos trabalhos desenvolvidos foram imprescindíveis para os códigos legislativos produzidos em Leão e Castela por Fernando III e Afonso X.

Entre as principais razões colocadas para esse movimento de renovação do direito, podemos apontar as reformas da Igreja iniciadas por Gregório VII e as diversas transformações sociais, culturais, políticas e econômicas em curso, que apresentavam uma crescente complexidade de questões e que colocavam em xeque a irracionalidade dos procedimentos jurídicos até então utilizados.

Essas transformações iniciadas no século XI, vão se cristalizar ao longo de todo o século XIII e é importante destacar que essa remodelação não se deu somente devido

260 O Decreto de Graciano é uma compilação legislativa datada de 1140 organizada pelo monge e professor de teologia Graciano. Tinha por objetivo harmonizar e conciliar as diferentes, e muitas vezes discordantes, fontes jurídicas existentes na Igreja. Sua obra foi fundamental para a criação e organização de uma doutrina eclesiástica. 
aos conteúdos ou a matéria jurídica em si, mas relacionada também à questões políticas e relações de poder.

\begin{abstract}
Finalmente, allá por el siglo XII, la Edad Media asiste a la invención de nuevas formas de justicia y de procedimientos judiciales. Esta "invención" - es necesario decirlo - está ligada a formas y condiciones de possibilidad del saber que no están vinculadas simplesmente al resultado de un "progreso de la racionalidad", sino que fueron el resultado de transformaciones en la estructura política que las hicieron posibles y necesarias. Esto es: la aparición de una nueva forma de estabelecimiento de la verdad (y de todas las prácticas judiciales derivadas de ella) está ligada a relaciones de poder muy precisas, y la transformación en el enfoque de la "verdad jurídica" debe ser apreciada a la luz de tales relaciones. (FONSECA, 2012, p. 29-30).
\end{abstract}

Isso é bem verdade para o caso da monarquia castelhana, onde o rei passou a se utilizar da ideia de que ele é o representante de Deus no mundo material e o responsável por exercer a justiça na terra, cuidando para que toda a sociedade se conserve em paz e bem. Logo, podemos perceber que não há um afastamento do caráter divino da justiça, mas novas interpretações de como o sagrado e o laico se inter-relacionam.

Se Deus não é mais aquele que decide diretamente se alguém é culpado, como nos ordálios, ele designa aos reis a obrigação de garantir que essa justiça seja feita em seus reinos. É a ideia do Rei-juiz que se inspira no Deus-juiz, ou seja, a justiça real é a aplicação no mundo material da justiça divina no mundo espiritual.

Conforme argumenta José Manuel Nieto Soria (1997), ao tratar do poder real em Castela, houve a "transposición concreta de normas y conceptos desde la teología y el derecho divino y eclesiástico al nuevo derecho régio, com todas sus potencialidades autoritarias para el modelo de realeza que se proyectaba." (SORIA, 1997, p. 56-57).

Dessa forma, a análise das fontes jurídicas produzidas tanto no reinado de Fernando III quanto no de Afonso X, mostra a continuidade de um projeto cujo objetivo maior era a centralização política e a organização interna do reino, com fins de afirmação da legitimidade de ambos os monarcas. O controle da justiça, e por consequência do processo judicial, era mais uma ferramenta nesse sentido, uma estratégia de ratificação do poder do governante e maneira de garantir o controle social e territorial. 
Uma observação detalhada dos primeiros dois livros do Fuero Juzgo e do Fuero Real deixa ver essa tentativa de organização do processo judicial, estabelecendo-se diversas disposições sobre sua estrutura, as figuras que nele atuam, os procedimentos para as demandas, entre outros. As testemunhas têm destaque especial nas duas obras, obtendo títulos específicos que discorrem amplamente sobre o assunto e abordam variadas questões relativas a elas.

Assim, com vias de melhor compreender o papel das testemunhas e suas formas de atuação nos pleitos, entendendo que a maneira mesmo com que estes foram organizados era parte de um projeto de centralização monárquica, nos propomos a analisar em uma perspectiva comparada ambos os fueros no tocante a este aspecto.

\section{O estabelecimento do Fuero Juzgo e do Fuero Real}

O Fuero Juzgo é a versão castelhano-leonesa do Liber Iudicum, a antiga legislação hispano-gótica, que foi traduzido para o vernáculo durante o reinado de Fernando III, que governou no período de 1217 a 1252. Ele efetivou a unificação dos reinos de Leão e Castela em 1230, em um esforço expansionista que já vinha sendo empreendido pelo menos desde a conquista de Toledo, em 1085, por Afonso VI (RUCQUOI, 1992, p. 65).

Após a unificação dos reinos fez-se necessário fortalecer o poder monárquico e uma das estratégias utilizadas foi a organização da justiça. Buscando a manutenção do controle político e o ordenamento do convívio social, necessário frente a uma população tão heterogênea, o direito foi uma importante ferramenta. Assim, o monarca iniciou a concessão do Fuero Juzgo às regiões conquistadas em Andaluzia e Murcia por volta de 1241, inicialmente tentando conter a pluralidade de fueros vigentes por todo o reino (REIS, 2007, p. 165).

Nesse sentido, essa tradução era parte de um projeto que visava delinear as fronteiras do reino frente aos muçulmanos, atender aos interesses dos nobres locais e garantir a unidade e organização do reino. 


\begin{abstract}
No campo jurídico, Fernando III investiu na elaboração de um projeto de unificação jurídica que demolisse o particularismo de ordenamentos que caracterizava o reino castelhano em decorrência da política anterior de concessão foral. [...] 0 monarca mandou, então, traduzir para o romance $o$ Liber Iudiciorum a que deu o nome de FJ [Fuero Juzgo]. Texto que tinha a seu favor o alto valor simbólico que possuía por ser considerada a fonte primordial do direito visigodo. Era garantida a este texto, portanto, a tradição e a antiguidade necessária para estabelecer-se como base o direito da corte fernandina. O FJ possuía duas características primordiais: a heterogeneidade temática e a defesa clara do poder centralista monárquico. (SILVEIRA, 2016, p. 7).
\end{abstract}

Ainda sobre a escolha pela tradução deste ordenamento jurídico em específico, segundo Ana Maria Barrero, explica-se por ser um texto de reconhecida autoridade; por dispor de uma série de assuntos ainda considerados vitais para aquelas comunidades; pelo seu alto valor simbólico em razão da sua origem, mas principalmente, porque "se reserva al Rey la posibilidad de cubrir sus insufuciencias, dictar nuevas normas; en definitiva, de crear derecho" (BARRERO, 2001, p. 126).

O Fuero Juzgo, na edição utilizada neste artigo, está dividido em XII livros, 55 Títulos, e 599 leis. Elas tratam, dentre outras disposições, das relativas à autorização do divórcio, dos diferentes tipos de contratos e dos temas relativos à questão da propriedade. Seus dois primeiros livros falam sobre o que é a lei e seus elaboradores; o pleito, seus partícipes e funcionamento, bem como os procedimentos a serem seguidos pela pessoa posta "en juicio".

Sobre a quantidade de manuscritos do Fuero Juzgo, há mais de trinta edições. Em nossa análise, utilizaremos a Edición de la Real Academia Española, 1815, publicada pela Imprenta Nacional de La Agencia Estatal Boletín Oficial del Estado, no ano de 2015.

Afonso X, cujo reinado estendeu-se de 1252 a 1284, seguiu por um caminho semelhante e não apenas manteve o projeto jurídico de seu pai, como o ampliou e modificou, renovando o direito castelhano. Primeiramente ele continuou a conceder fueros antigos às cidades que iam sendo conquistadas, porém logo deu início à redação do seu próprio aparato jurídico, cercando-se de um grupo de legistas formados nas principais universidades da época. Importante ressaltar também o fato dos dois 
monarcas terem editado seus códigos jurídicos em castelhano, o que facilitava a disseminação dos mesmos.

As obras jurídicas afonsinas foram baseadas tanto no direito romano e canônico, quanto no direito comum. Importante ressaltar que com a renovação jurídica já em curso nos últimos séculos, conforme abordado anteriormente, nada mais natural do que ter presente nestas obras influências e alterações frutos daquela renovação.

Entre as obras jurídicas afonsinas, uma das principais é o Fuero Real, que apresenta um total de mais de quinhentas leis, divididas em cerca de setenta títulos organizados ao longo de seus quatro livros. Destes, os dois primeiros dispõem sobre o funcionamento do pleito, as atribuições e atuações dos funcionários públicos, os prazos, entre outros, e os dois últimos da disposição de leis para ordenação do convívio social.

Há mais de 40 manuscritos preservados do Fuero Real. Contudo, segundo Jerry R. Craddock, "el texto tiene una extraordinaria fijeza", sendo raras as variações textuais (CRADDOCK, 2008, p. 11). Em nossa pesquisa, utilizamos a Edición de La Real Academia de la Historia, 1836, publicada pela Imprenta Nacional de La Agencia Estatal Boletín Oficial del Estado, no ano de 2015.

Este código é, portanto, uma compilação de leis que unificava a pluralidade de direitos então existentes em uma única obra jurídica, atuando no fortalecimento do poder monárquico através da centralização, visando substituir as cartas municipais e "reservar ao rei o poder judicial e notarial nas principais cidades do reino". (RUCQUOI, 1995: 179). Percebe-se assim a continuidade feita por Afonso $X$ do projeto político de manutenção da autoridade central estabelecido por seu pai.

Se o direito foi mobilizado enquanto um aparato útil ao maior controle por parte destes monarcas, com ele todos seus aspectos internos, como o processo judicial e, principalmente, os envolvidos nessas contendas, as testemunhas por exemplo. Já que legislar sobre esses "atores" processuais era também uma forma de ordenar a própria sociedade. 
Embora saibamos que os dois códices se inter-relacionam no sentido de um programa político de reinado, ainda não temos as dimensões exatas do alcance dessas inter-relações em seu conteúdo, nem até que ponto foi preciso alterar, inserir ou retirar dispositivos para dar andamento aos objetivos da monarquia. As testemunhas, por exemplo, são amplamente regulamentadas nas duas fontes, resta saber quais os limites para as aproximações ou afastamentos de uma para outra.

\section{O estudo das testemunhas em perspectiva comparada}

As leis referentes às testemunhas encontram-se no Livro II, tanto no Fuero Juzgo quanto no Fuero Real. A partir deste momento serão usados FJ e FR para se referir às obras respectivamente, visando dinamizar a leitura.261 No FJ o Título IV é chamado "De las testimonias e de lo que testimonian" e consta de treze dispositivos, já no FR o Título VIII "De las testimonias e de las pruevas" engloba um total de vinte e uma leis.

$\mathrm{Na}$ comparação da legislação sobre as testemunhas, vamos nos pautar no pressuposto de Jurgen Kocka, de que as unidades comparativas podem ser separadas umas das outras e analisadas individualmente, considerando cada caso como um fato independente. Para esse autor, "essa metodologia permite identificar questões e problemas que, de outro modo, poderiam ser negligenciados." (KOCKA, 2014, p. 283)

Assim, buscamos identificar e analisar as semelhanças, diferenças e as particularidades contidas nas normativas sobre o papel das testemunhas apresentadas no FJ e no FR, por meio da comparação sistemática dos dados levantados. Para tanto, utilizamos três comparáveis, ou seja, temas de comparação: 1) Quem pode testemunhar em um pleito; 2) Quem não pode ser testemunha no pleito; 3) Quem dá falso testemunho; Empregando a proposta de Kocka, passamos a apresentá-las a seguir.

A respeito das testemunhas aceitas em um processo, a Lei I do FR afirma que em todo pleito são válidos os testemunhos de dois omes buenos, enquanto a Lei III do FJ

261 Adotaremos a seguinte notação para fazer referências às leis, de ambos os fueros, após suas respectivas citações: (FUERO, Livro, Título, Lei). 
estabelece a mesma norma quanto à quantidade de testemunhas e a necessidade de que sejam omes buenos, mas se diferencia do FR ao dizer que esses testemunhos são válidos onde a lei mandar e não em todo pleito.

Embora exista um debate acerca que quem eram esses omes buenos, em linhas gerais podemos dizer que eram pessoas notáveis do reino, proprietários de terras e parte da nobreza, alta ou baixa. Esta condição era, muitas vezes, uma mescla entre aspectos morais e econômicos, sendo ambos necessários para se fazer a justiça (DIAZ, 1989, p. 233-234).

É possível pensar que a concessão do FJ se dava principalmente às regiões que iam sendo reconquistadas, com o objetivo de lhes garantir uma normatização de acordo com os pressupostos unificadores pretendidos pelo monarca.

\begin{abstract}
A escolha do Fuero Juzgo para ser difundido para toda a Andaluzia e o reino de Murcia deveu-se, primeiramente, a fatores de ordem prática: sua melhor adequação às cidades de tradição moçárabe; o êxito da concessão desse código como Fuero de Toledo às zonas circunvizinhas conquistadas por Fernando III, além da sua característica de código amplo e completo. Existe também uma razão ideológica: seu caráter de código oriundo da atividade legislativa dos reis visigodos; portanto, mais propício ao resgate da unidade pretendida por Fernando III e ao fortalecimento do poder real almejado pelo monarca. (REIS, 2013, p. 280)>
\end{abstract}

No entanto, enquanto Fernando resguardava certo domínio jurídico em algumas regiões como Leão, Toledo e Andaluzia, apesar da pluralidade de fueros que ainda existia, isso não ocorreu em Castela, que utilizava seus próprios costumes ou fazañas. Dessa maneira, durante o reinado de Afonso X, havia a necessidade de se garantir que essas regiões estariam de fato sob a autoridade do rei, e a distribuição de um fuero que vigorasse em todo o reino, foi uma das estratégias utilizadas por ele.

Voltando às testemunhas, percebemos que se o FJ determina que os testemunhos de dois omes buenos valem onde manda a lei, isso poderia significar uma brecha para outras normativas que também estavam em vigor. Já no FR, este ponto está mais bem delimitado ao dizer que isso vale para todo pleito, pois esse código mesmo tinha a pretensão de ser único para todo o reino, conforme estabelecido por lei: 
Bien sofrimos e queremos que todo ome sepa otras leyes por ser mas entendudos los omes e mas sabidores, mas non queremos que ninguno por ellas razone nin judguea, mas todos los pleitos sean judgados por las leyes deste libro, que nos damos a nuestro pueblo, e mandamos guardar. (FR, I, VI, v).

Ainda sobre a quantidade de testemunhas, Jesús Vallejo (1985) argumenta a respeito do princípio geral que pressupõe a necessidade de se ter, no mínimo, dois testemunhos para que a prova seja validada. Esta ideia já era discutida por canonistas como Paucapalea, quando este buscava argumentos bíblicos que fundamentassem os processos judiciais das cortes eclesiásticas. A passagem de Deuteronômio onde Moisés afirma que a verdade pode ser encontrada nas palavras de duas ou três testemunhas foi a justificativa encontrada por ele para validar esse preceito (PENNINGTON, 2016, 138).

Sobre a questão do juramento, os dois fueros apresentam dispositivos que alegam ser este um ato indispensável para validar o testemunho. No FJ é a Lei II, "Que las testimonias non devem seer creydas, si non iuraren;", que estabelece que ninguém pode ser testemunha se não jurar. Já no FR, a Lei IX coloca o mesmo princípio a respeito do juramento, e diz que ninguém deve ser recebido como testemunha se não jurar.

Apesar das duas leis parecerem muito semelhantes, o FR estipula uma punição mais diretamente ligada à recusa de juramento, que é o pagamento àquele que perdeu com a recusa do valor referente à perda. No FJ a punição à recusa do juramento se confunde com o ato de não dizer a verdade ou mesmo se abster de dizer o que se sabe, e está separada em proibição de ser testemunha novamente, para homens de classe alta, ou a mesma punição com o adicional de receber 100 açoites 262 e ser difamado, caso seja homem de baixa classe ou homem livre.

No entanto, Vallejo ressalta que no FR é considerado falso testemunho não apenas o relato contrário à verdade, mas também o ocultamento deliberado dessa verdade pela testemunha, que está estabelecido no Livro IV, Título XII que trata dos

262 Esta era uma penalidade imposta àqueles considerados criminosos e delinquentes, podia ser usado uma espécie de chicote ou bastão para aplicar o castigo. 
falsários (VALLEJO, 1985, p.531). Embora se aproxime da disposição do FJ, o FR não diferencia penalidades por diferentes classes sociais neste dispositivo.

Analisando quem pode ser testemunha em ambos os fueros, já destacamos a resposta afirmativa aos "omes buenos", que no FR não somente têm liberdade para dar testemunho, mas são ainda considerados para outras funções como pesquisadores (FR, II, VIII, III). Ainda no FR, aqueles considerados muito pobres poderiam ser testemunha se fossem de "buena vida e de buontestimonio" (FR, II, VIII, IX), e também os alcaides se não houvesse nenhum impedimento por lei.

No caso das mulheres, o FJ permite que sejam testemunhas a partir dos 14 anos de idade: "E ninno ó la ninna pues que ovieren complidos XIIII annos, mandamos que puedan seer testemonias en todo pleyto." (FJ, II, V, XII).

No FR, "no pueda testimoniar contra outro [...] ninguno que no haya diez y seis años cumplidos" (FR, II, VIII, IX). Além da diferença de faixa etária estabelecida para as testemunhas no pleito, a lei especifica que o testemunho feminino só era permitido nos assuntos ditos "mulheris", ou nos que pudessem acarretar algum tipo de mal ao rei:

\footnotetext{
Toda muger vecina o fija de vecino pueda testiguar en cosas que fueren fechas o dichas em baño, e en forno, e en molino, e en rio, e en fuente, e sobre filamentos, e sobre teximientos, e sobre partos, e acatamiento de muger, e em otros fechos mugeriles, e non em otras cosas si non em las que manda la ley, si non fuer muger que ande em semeianza de varón, que no queremos que testimonie si non em cosa que sea contra rey o contra su señorio. (FR, II, VIII, VIII).
}

A maioria das leis que tratam da condição feminina no FR está voltada para questões que, apesar de parecerem estar restritas ao âmbito privado, interferem diretamente na vida pública, como a normatização do casamento, da herança e das implicações relativas ao adultério.

No caso das leis que tratam da participação feminina em processos judiciais, quase sempre se mostram muito restritivas, como pudemos ver no trecho da citação anterior. Nele limitam-se os testemunhos das mulheres aos fatos ocorridos no âmbito privado ou sobre assuntos considerados do âmbito feminino, como partos por exemplo. 
Há uma particularidade, na lei do FR, diretamente ligada aos papéis sociais destinados a homens e mulheres da sociedade medieval, definidos a partir de atributos dirigidos a cada elemento, tais como a virilidade masculina e a castidade feminina. Imbuídos destes papéis sociais, homens e mulheres deveriam submeter-se a um processo de disciplinarização e de enquadramento de seus corpos de forma a poder desempenhar adequadamente os papéis que a sociedade lhes delegou. (L'HERMITTELECLERQC, 1992, p. 258)

Caso a lei considerasse que a mulher adotava um comportamento atribuído ao masculino, não the seria permitido testemunhar: "si no fuere muger que anda en semejanza de varon: que non queremos que testemonie" (FR, II, VIII, IX).

Essa exclusão juridicamente legitimada baseava-se no fato que,

O controle que as autoridades laicas e eclesiásticas pretendiam exercer sobre os corpos de homens e mulheres passava por dois movimentos contínuos e complementares: o controle das relações matrimoniais e das sexuais. Isto porque o discurso eclesiástico só considerava como legítima a sexualidade exercida no casamento e o direito real, que em grande parte dispunha dos referenciais teológicos, corroborava com esta noção, punindo os delitos sexuais que colocassem em risco a legalidade da instituição matrimonial. (CARRASCO MANCHADO, 2008, p. 123)

Esse critério de exclusão, pautado na sexualidade da testemunha, não se limitará ao sexo feminino; o "home que anda em semejanza de muger" (FR, II, VIII, IX), também será alvo desse impedimento, na matéria do FR que trata dos que não podem ser testemunhas, conforme veremos a seguir.

As leis do FJ e FR que tratam dos aspectos referentes aos que não podem testemunhar, adotam como critérios restritivos os desvios de conduta social, religiosa, sexual e legal; vínculos parentais e servis; faixa etária; capacidade mental; boa ou má índole; condição econômica das testemunhas. Elas evidenciam a influência do direito eclesiástico e das normas costumeiras na elaboração das leis, bem como a contribuição desses direitos nos ideais de afirmação da autoridade real, almejados por Fernando III e Afonso $X$. 
No FJ, não são válidos os testemunhos dos homicidas; dos que preveem o futuro e dos que vão consultá-los; dos que dão ervas; dos ladrões; dos pecadores; dos que violam as mulheres; dos perjuros e daqueles que se encontram sob a condição servil:

Los omizeros, é los sorteros, é los servos, é los ladrones, é los pecadores, é los que dan yervas, é los que fuerzan las muieres, é los que dixióron falso testemonio, é los que van por pedir conseio à las sorteras: estos non deven recebir por testemonios en nenguna manera. (FJ, II, IV, I)

O caráter definitivo da restrição de cada um fica claro na lei, enquanto que, no FR, há casos onde esse impedimento pode ser revogado, como o do excomungado e o de um homem que tenha inimizade com outro. Isso significa que, sendo a pena de excomunhão anulada e a inimizade desfeita, os envolvidos nessas condições poderão testemunhar nos pleitos em que forem intimados a depor.

Além dessas duas exceções, e de alguns casos em comum com o FJ, tais como os ladrões, os adivinhos e seus consulentes, os homicidas, os servos, o pecador/herege, os que dão ervas e os que deram falso testemunho, uma série de outras categorias são impedidas de testemunhar no FR, em razão de suas condutas, conforme citado na lei IX:

\begin{abstract}
Otrosí, no pueda testimoniar contra otro que aya parte en la demanda, [...], ni home que mató home à tuerto, ni traydor, ni alevoso, ni descolmugado, mientra lo fuere, ni herege, ni siervo, ni ladron, ni home que ande fuera de su orden sin licencia de su mayor, ni home que dá yervas à otro por facerle mal, ni robador conocido, ni home que no ha memoria, ni home que dixo falso testemunho, ni el que es dado por sentencia por falso de qualquier falsedad, ni perjurado, ni adevino, ni sortero, ni los que van à ellos, ni alcahuete conoscido, ni home que anda en semejanza de muger, ni aquel que haya natura de home y de muger, ni enemigo contra su enemigo, mientra duráre la enemistad, é ningun paniguado por, ni home muy pobre, si no fuere probado por de buena vida, y de buen testemonio. (FR, II, VIII, IX).
\end{abstract}

Por suas particularidades, algumas interdições abrem possibilidades a reflexões que não serão discutidas nesse texto, mas que, segundo o pressuposto de Kocka (2014), ao ser analisadas separadamente, no apontariam questões relevantes sobre a sociedade castelhana no século XIII, a partir dos textos jurídicos vigentes naquele território: a do religioso que deixa a ordem sem licença de seu superior, cuja sanção civil, cremos, se 
somaria às punições próprias das regras a qual estivesse vinculado; do homem que não tem memória, que nos remete às questões de incapacidade mental e do tratamento dado aos portadores de deficiências naquele período; o cafetão conhecido, onde três questões são colocadas em evidência: a exploração sexual, a prostituição e a publicização dessas atividades, bem como a exposição negativa de seus protagonistas.

A boa fama e a pobreza também são aspectos relevantes quando se trata de que pode ou não testemunhar além do caráter de traiçoeiros e traidores. E, como havíamos dito anteriormente, a questão da sexualidade daquele que testemunha aparece mais vez na lei, dessa vez, em relação ao "home que anda en semejanza de muger, ni aquel que haya natura de home y de muger" (FR, II, VIII, IX)

Esse trecho do FR nos traz duas características "desviantes": uma de "andar semelhante a uma mulher"; outra a de ter a "natureza de homem e de mulher". Daí, questionamos: haveria, na sociedade castelhana, elementos que se travestiam? Ou, dada a diversidade populacional e cultural naquele território, seria considerado como feminino algum tipo de vestuário característico de alguma etnia que por ali circulava? $\mathrm{E}$ quanto à natureza feminina e masculina do homem expressa no texto, diria respeito, exclusivamente, à prática social com os dois sexos, ou também a gestos, expressões e outros comportamentos adotados por ele o classificavam como de "natureza dupla"?

Destacamos que nenhuma das questões apontadas nas particularidades sobre quem não pode ser testemunha até aqui elencadas, não serão aprofundadas em nosso texto, contudo as elencamos por alinharem-se à nossa proposta de buscar identificar e analisar as semelhanças, diferenças, bem como as particularidades contidas nas normativas sobre o papel das testemunhas apresentadas no FJ e no FR, por meio da comparação sistemática dos dados levantados.

O último aspecto restritivo sobre as testemunhas diz respeito aos graus de parentesco entre os envolvidos no pleito. Tanto o FJ em sua lei XIII, quanto o FR na lei IX, decretam que pais, filhos, irmãos, tios, primos e sobrinhos, não podem ser testemunhas contra estrangeiros, exceto se o pleito for entre parentes de uma mesma linhagem, ou se outro homem livre não pudesse ser testemunha no pleito. 
À luz do que foi dito anteriormente sobre as mulheres, apesar de parecer uma questão restrita ao âmbito do privado, questões patrimoniais eram relevantes à nobreza e qualquer possibilidade de favorecimento de grupos nobiliárquicos em detrimento de um estranho, interferiria direta e negativamente na vida pública devendo, portanto, ser coibido pelas leis régias.

Para analisarmos as leis que abordam a nossa última variável - o falso testemunho - é preciso antes dizer que elas não se encontram apenas nos dispositivos especificados, no FJ a Lei VI "De los que dizen falso testimonio" e no FR a Lei XIII, mas pode ser subentendida em outras matérias ao longo do Título referente às testemunhas.

Na lei VI do FJ, são condenados por falso testemunho tanto o indivíduo que testemunhou, quanto um possível influenciador que o possa ter levado a cometer esse ato. Há uma diferenciação de classe social para determinar a punição a ser aplicada caso a mentira seja descoberta ou confessada, mas não anula-se o pleito exceto se o falso testemunho puder ser provado por documentos ou outras testemunhas.

Se for pessoa de alta classe deve pagar tudo o que fez o outro perder decorrente de seu ato e não mais poderá ser testemunha em pleitos futuros. Já se for de baixa classe e não puder pagar o dano infligido ao outro, deve ser entregue a ele como servo.

O FR em sua Lei XIII é muito parecido com a Lei VI do FJ ao dizer que se o falso testemunho for descoberto ou confessado este deve pagar àquele que prejudicou o valor de seu dano e, caso não possa pagar, fique sob poder dele, mas só até lhe ressarcir o que é devido. Um detalhe importante é que nesta lei o FR não distingue expressamente penalidades diferentes para alta e baixa classe. No entanto, isto não deve ser interpretado como sinal de uma legislação mais justa e igualitária nos termos que entendemos hoje.

A distinção feita na aplicação das penalidades e a permissão ou proibição de participação nas variadas esferas do processo mostram o lugar que cada um ocupava naquela sociedade. "A lei produzida não era igualitária, não reduzia todos os súditos ao 
mesmo status social, pelo contrário, marcava a diferenciação entre os indivíduos de forma acentuada." (SILVEIRA, 2017, p. 194).

Conforme visto anteriormente, a necessidade de duas testemunhas era importante, apesar de poderem ser aceitas em maior número, e estava relacionada com o princípio geral já estabelecido e fundamentado pelos canonistas com base nos escritos bíblicos. Assim, podemos pensar que o falso testemunho feria esse princípio de dois testemunhos como sendo a "verdade", e aos próprios preceitos bíblicos.

Além disso, feria também a ideia de "bem comum", ou seja, ao agir contrariamente às leis estabelecidas para garantir o bem de todos afrontava-se a comunidade como um todo, e não apenas o indivíduo a quem ele prejudicou. A noção de que o rei era o responsável por garantir que todos vivessem em paz e justiça foi bastante explorada principalmente por Afonso X em sua obra legislativa, o que revela uma tentativa de maior fortalecimento da autoridade real de um fuero para outro.

O FJ ressalta também em sua Lei VIII que quando uma testemunha confessar que disse mentiras e quiser dar novo testemunho este não valha e nem o pleito seja desfeito, exceto se puder ser provado, uma vez que sua palavra deixa de ser confiável.

\footnotetext{
La maldad de las falsas testimonias non saben prender mesura em dezir falsedad, mas ennader um periurio á otro. E por ende estos atales son condempnados de muerte segund la ley de Dios, porque son provados que dizen falsa testimonia contra su próximo. E nos querémos daquí adelantre toller que non puedan seer testimonias, ca non devem seer muertos tan solamientre por la ley de Dios, mas demas por la ley de los omnes. (FJ, II, IV, VIII)
}

A Lei IX, "De los que aduzen otros omnes que digan falso testimonio", apresenta ainda outra normativa relativa ao falso testemunho dado com a intenção de fazer homem livre ou liberto cair em servidão ou libertar servos alheios. O FR não traz nada especificamente sobre isso neste Título.

Outras leis que não são expressamente sobre falso testemunho, mas estão relacionadas e podem ser entendidas como maneiras de evitar que isso ocorra são aquelas que dispõem sobre o testemunho dado presencialmente, diante do alcaide. $\mathrm{A}$ Lei V do FJ estabelece "Que el testigo non puede testimoniar por letras, mas por sí 
mismo", ou seja, deve testemunhar presencialmente, exceto se forem idosos, doentes ou morarem muito distante.

Nesse caso, o testemunho dado em seu nome por outra pessoa é válido, desde que feito segundo o procedimento dito na lei. A Lei XII do FR trata da mesma questão de igual maneira ao dizer que ninguém mande testemunho por carta, mas diga-o diante do alcaide ou de quem ele mandar. A Lei $X$ do FR coloca as regras para tomar testemunho de pessoas doentes ou que morem distante, que nesse caso pode ser por escrito, desde que diante do alcaide.

Ambos os fueros regulam de forma parecida estes casos e abrem exceções para o recebimento de testemunhos por escrito, desde que sejam dados diante do alcaide responsável pelo pleito, ou por outro alcaide designado no caso de pessoas que residam longe do local onde é a jurisdição do dito pleito. Pode-se perceber aqui que o escrito estava começando a ganhar força, embora o oral ainda fosse muito importante para os processos naquele momento.

A Lei III do FJ, por exemplo, trata "De la testimonia que dize uma cosa, y el escripto dize outra;", colocando que quando se tem um testemunho e algo por escrito que se diferencie dele, vale o que está escrito. E, caso o juiz necessite de maiores provas sobre o que está em disputa, ele primeiramente vai comparar o escrito da testemunha com outros feitos por ela e só depois disso tomar o seu juramento como prova.

Em geral, os litigantes podem fazer objeções às testemunhas, como dito na Lei XVI do FR e nas Leis VII e VIII do FJ, desde que o façam dentro do prazo da lei. Se não fizerem o alcaide proceda o julgamento normalmente recebendo os testemunhos como verdadeiros. As testemunhas devem sempre ter conduta moral ilibada, sendo reconhecidos e respeitados pela sua comunidade. Finalizadas a análise das comparáveis escolhidas por nós, passaremos às considerações finais do nosso trabalho. 


\section{Conclusão}

A nossa proposta foi realizar uma análise comparativa sobre a atuação das testemunhas nos processos judiciais, contidos nos textos jurídicos em vigor nos reinados de Fernando III e de seu filho e sucessor, Afonso X, na Castela do século XIII.

A crescente racionalização do processo judicial, ocorrida a partir do século $\mathrm{XI}$, incluiu a incorporação de novas formas de provas, entre elas a testemunha e o testemunho, que passaram a ter cada vez mais importância. Essas mudanças refletiramse no direito aplicado pelas monarquias, como no caso da castelhana, onde ambas as obras aqui analisadas reservam especial atenção a esse tópico.

Na comparação da legislação sobre as testemunhas, contida no Fuero Juzgo e do Fuero Real, a partir de três variáveis - quem pode testemunhar, quem não pode ser testemunha e quem dá falso testemunho no pleito, podemos elencar algumas considerações:

As duas leis mencionam, a participação de homens e mulheres no pleito: os omes buenos, como pessoas de reputação ilibada, advindos do ramo nobiliárquico e de boa condição econômica. Tais requisitos, não estão evidenciados nas leis que tratam das mulheres como testemunhas e limita os seus testemunhos aos assuntos considerados mulheris.

Havia uma idade mínima para que os testemunhos de homens e mulheres fossem válidos, que se diferem nos dois fueros: no FJ, a idade mínima, são de 14 anos, já no FR, ambos deveriam ter 16 anos completos.

Sobre as restrições, várias categorias de agentes sociais figuram nos dois textos jurídicos e sua exclusão do processo são, em sua maioria, em função das más condutas de cada um dos agentes, tais como os homicidas, os adivinhos, ladrões, cafetões. Contudo, elas não se restringem a esses aspectos e a insanidade mental, a pobreza a condição servil e comportamentos ligados à sexualidade também aparecem como particularidades nas leis. 
Quanto aos falsos testemunhos, eles poderiam ser tanto descobertos quanto confessados, sendo ambos passíveis de punições diferenciadas de acordo com o status social e econômico dos envolvidos.

Com base na análise, concluímos que as fontes trazem, em seu conteúdo, similitudes, diferenças e particularidades a respeito das testemunhas, baseadas, em aspectos tais como, o status social, econômicos além da conduta.

A partir do momento em que cada monarca foi exercendo o seu papel de promotor da justiça, percebemos novos ajustes nas leis, envolvendo os graus de parentesco, maiores especificações acerca de alguns dispositivos, sem perder, de vista a própria renovação do direito que já estava ocorrendo naquele momento tanto no âmbito civil, como no eclesiástico.

Todo esse empenho era parte do projeto de centralização e afirmação régia, empreendido, primeiro, por Fernando III, seguido por seu filho e sucessor Afonso X naquele território castelhano.

\section{Referências Bibliográficas}

\section{Documentação}

FUERO Juzgo. Edición de la Real Academia Española, 1815. In: Colección Leyes Históricas de España. Estudio preliminar de Santos. M. Coronas. Madrid: Imprenta Nacional de La Agencia Estatal Boletín Oficial del Estado, 2015.

FUERO Real de Alfonso X El Sabio. Edición de La Real Academia de la Historia, 1836. In: Colección Leyes Históricas de España. Estudio preliminar de Antonio Pérez Martín. Madrid: Imprenta Nacional de La Agencia Estatal Boletín Oficial del Estado, 2015.

\section{Bibliografía}

ÁLVAREZ DIAZ, Salvador. Los omes buenos en las villas realengas de Álava, 1168-1332. Jornadas sobre Cortes, Juntas y parlamentos del Pueblo Vasco, San Sebastián, Cuadernos de Sección, Derecho, 6, p. 231-239, 1989. 
BARRERO, Ana Maria. El processo de formación del derecho local medieval através de sus textos: Ios fueros castelhanos-leoneses. In: IGLESIA, J. I. de D. (Coord.). SEMANA DE ESTÚDIOS MEDIEVALES. 1., Nájera, 1990. Actas... Logroño: IER, 2001. p. 91-130.

CARRASCO MANCHADO, Ana Isabel. Entre el delito y el pecado: el pecado contra naturam. In: CARRASCO MANCHADO, Ana Isabel; RÁBADE OBRADÓ, María Pilar (coord.). Pecar en la Edad Media. Madrid: Sílex, 2008, p. 113-148.

FONSECA, Ricardo Marcelo. Introducción teórica a la historia del derecho. Madrid: Universidad Carlos III de Madrid, 2012.

KEMMERICH, Clóvis Juarez. O direito processual na Idade Média. Porto Alegre: Edição Kindle, 2016.

KOCKA, Jürgen. Para além da comparação. Revista Esboços, Florianópolis, v. 21, n. 31, p. 279-286, 2014. LE GOFF, Jacques. História e Memória. Campinas, SP: UNICAMP, 1990

L'HERMITTE-LECLERQC, Paulette. "Las mujeres en la orden feudal. (siglos XI y XII)". In: DUBY, Georges; PERROT, Michelle (org.). Historia de las mujeres. La Edad Media. La mujer en la familia y en la sociedad. Madrid: Taurus, 1992. p. 247-300, p. 258.

NIETO SORIA, Juan Manuel. Origen divino, espíritu laico y poder real en la Castilla del siglo XIII. Anuario De Estudios Medievales, España, 27(1), p. 43-101, 1997. Disponível em: https://doi.org/10.3989/aem.1997.v27.i1.642. Acesso em: 05 jan. 2021.

PENNINGTON, Kenneth. The jurisprudence of procedure. In: PENNINGTON, Kenneth; HARTMANN, Wilfried. (edit). The history of courts and procedure in medieval canon law. Washington, DC: The Catholic University of America Press, 2016. p. 125-159.

REIS, Jaime Estevão dos. Território, legislação e monarquia no reinado de Alfonso $X, o$ Sábio (1252-1284). 2007. 250 f. Tese (doutorado) - Universidade Estadual Paulista, Faculdade de Ciências e Letras de Assis, São Paulo, 2007. Disponível em: http://hdl.handle.net/11449/103168. Acesso em: 11 ago. 2020.

REIS, Jaime Estevão dos. O panorama legislativo dos territórios da Coroa de Castela no início do reinado de Alfonso $X$, o Sábio. Mirabilia: Electronic Journal of Antiquity, Middle \& Modern Ages, n. 16, p.260-285, 2013. Disponível em:

https://dialnet.unirioja.es/servlet/articulo?codigo=4335163. Acesso em: 04 mar. 2021.

RUCQUOI, Adeline. De los reyes que non son taumaturgos: los fundamentos de la realeza em España. Relaciones: Estudios de Historia Y Sociedad, México, v. 13, n. 51,p. 55-100, 1992.

História Medieval da Península Ibérica. Lisboa: Editorial Estampa, 1995. 
SILVEIRA, Marta de Carvalho. A lei na Idade Média. Penalidades corporais em Castela. Curitiba: Editora Prismas, 2017.

. As penalidades corporais: uma análise comparativa do Fuero Real e do Fuero Juzgo. In: XVII Encontro de História da Anpuh-Rio - Entre o local e o global, 2016, Nova Iguaçu. Anais do XVII Encontro de História da Anpuh-Rio - Entre o local e o global, 2016.

VALLEJO, Jesús. La regulación del proceso em el Fuero Real: desarrollo, precedentes y problemas. Anuario de historia del derecho español, n. 55, p. 495-704, 1985. Disponível em:

https://www.boe.es/biblioteca juridica/anuarios derecho/articulo.php?id=ANU-H1985-10049500704. Acesso em: 2 nov. 2019. 